\title{
An Enterprise Architecture Approach towards Environmental Management
}

\author{
Ovidiu Noran \\ Griffith University Australia, School of ICT \\ O.Noran@griffith.edu.au
}

\begin{abstract}
Environmental responsibility is fast becoming an important aspect of strategic management as the reality of climate change settles in and relevant regulations are expected to tighten significantly in the near future. Many businesses react to this challenge by implementing environmental reporting and management systems. However, the environmental initiative is often not properly integrated in the overall business strategy and as a result the management does not have timely access to appropriate environmental information. This paper argues for the benefit of integrating the environmental management (EM) project into the continuous enterprise architecture (EA) initiative present in all successful companies. This is done by demonstrating how a reference architecture framework and a metamethodology using EA artefacts can be used to co-design the EM system and the organisation in order to achieve an appropriate synergy.
\end{abstract}

Keywords: Environmental management, enterprise architecture.

\section{Introduction}

The existence and success of businesses depends not only on their economic sustainability but also on their impact on the natural environment and the way they treat their workers. This basic truth was emphasized by Elkington's (1998) Triple Bottom Line (TBL) approach to business sustainability: one must achieve economic bottom-line performance but also environmental and social accomplishment. Thus, Blackburn (2007) compares economic sustainability to air and environmental and social sustainability to food: the first is more urgent but not more important than the second. The '2Rs' (Respect for humans and judicious Resource management) are another essential component of overall sustainability of the business. Hence, a successful enterprise must take a whole-system approach to sustainable development (UN World Commission on Environment and Development 1987). This paper focuses on the challenges presented by the proper integration of the environmental sustainability aspect in the business and proposes a solution addressing these challenges based on an EA approach.

\section{Tackling Environmental Management Integration}

To date most EM efforts within an enterprise are rather disjointed, i.e. specific to business units and not properly supported by the ICT infrastructure. This means that 
a) different units approach environmental sustainability in different levels of detail and at a different pace, b) there is a possible loss of aggregate capabilities due to the various departments not 'understanding' each other's approach to sustainability and c) top management cannot effectively use the information generated by the environmental reporting functions due to language, format, level of aggregation etc.

Strategic integration of EM is only achievable if the necessary information is at the fingertips of managers in the form and level of aggregation they need (Molloy 2007). Therefore the EM initiative must be accompanied by and integrated with changes in the enterprise's information system (IS), necessary to provide effective access to environmental information facilitating the decision-making process (Nilsson 2001; Molloy 2007). For the EM project to succeed in the long term, i.e. to determine permanent changes in the way people act, there will be a need for:

a) top-management support for the project champion(s);

b) sufficient authority and appropriate human / infrastructure resources;

c) a suitable strategy integrated in the general company strategic direction;

d) a cross-departmental approach.

The above-mentioned requirements match to a good extent the scope of typical enterprise architecture (EA) projects; it is therefore proposed here that EA could provide a solution to an integrated approach to the introduction of environmental aspects in the management and operation of all business units. This is desirable because a company whose architecture includes EM competencies and responsibilities in an integrated fashion will have the necessary agility and preparedness to cope with the challenges brought about by climate change, thus turning a potential weakness into strength. The EM project would involve some of the steps below:

a) identifying the business processes and their environmental impact (AS-IS);

b) defining a vision and concept(s) for the future state (the TO-BE),

c) eliciting and specifying requirements to reach the selected TO-BE state,

d) (re)designing the processes and policies according to these requirements

e) implementing the processes and policies previously designed;

f) continually monitoring the effects and

g) applying some of the previous steps for correction and enhancement.

These phases reflect the continuous improvement Plan-Do-Check-Act cycle (Shewhart 1986).

\section{Environmental Management Artefacts: A Brief Analysis}

Companies typically address the requirement to introduce environmental responsibility in their business units by attempting to implement some type of environmental reporting and environmental management system (EMS).

While an EMS is a step in the right direction, when implemented in isolation it may not trigger the cultural change necessary to achieve permanent environmental responsibility. Some authors (Coglianese and Nash 2001) argue that the implementation of an EMS alone is irrelevant in the absence of a real commitment to environmental 
improvements. Relevant regulation, for example ISO 14001:2004 (ISO 2004) only requires that an EMS be designed in such a way that companies can work toward the goal of regulatory compliance and seek to make improvements, not that the company actually achieves compliance with existing law.

Various reference models (frameworks, methods etc) and alternatives to EMS design have emerged. For example, Blackburn (2007) proposes a 'Sustainability Operating System' - in fact, a management method to achieve sustainability based on the Brundtland report (UN World Commission on Environment and Development 1987), the '2R's and the TBL approach applied to sustainability. Willard (2002) also recommends a TBL-based approach encompassing economy / profit, environment / planet and equity / people with seven benefits: easier hiring and retention, increased productivity, reduced manufacturing / commercial sites expenses, increased revenue / market share and reduced risk. Clayton and Redcliffe (1998) propose a systems approach to integration of sustainability aspects into the business and define the concept of environmental quality as capital (and thus the feasibility of 'tradable pollution').

EM frameworks aim to provide a structured set of artefacts (methods, aspects, reference models, etc) specialised for the EM area. Some examples are The Natural Step (TNS) Framework, using a systems-based approach to organisational planning for sustainability (Upham 2000), The Natural Edge Project (TNEP 2007) which proposes a holistic approach ('Whole System') taking into account system life cycle and the Life Cycle Management Framework for continuous environmental improvement (Hunkeler 2004).

Assessment and reporting frameworks aim to assist the measurement and reporting functions of the EMS. For example, the Life Cycle Assessment (LCA) method measures the environmental impacts of products or services relative to each other during their life cycles (EPA 2008). The Global Reporting Initiative's sustainability reporting framework (GRI 2002) contains reporting principles, guidance and standard disclosures potentially applicable to all types of businesses.

International Standards also cover the EM issue. ISO 14000:2004 is a set of reference models for EMS setup, life-cycle assessment, environmental auditing of processes, environmental labelling and environmental performance evaluation. ISO 14001:2004 deals specifically with EMS-s, aiming to provide a framework for a holistic and strategic approach to the organization's environmental policy, plans and actions (ISO 2004). Standards provide a good starting and reference point for design and assessment; however, as mentioned current EM standards do not define EM performance levels that the company should meet.

Many of the above-mentioned artefacts recognize the need to analyse the life cycle of the products. However, in reality it is often required to also take into account other life cycles - such as those of the host company, of its IS, of the projects set up to (re)design the IS and create the EMS and especially of the EMS itself. It is also necessary to analyse the interactions between these entities in that context. This approach provides a holistic perspective, allowing to represent and understand the business, the relevant projects, the target EMS, its impact on the IS and to identify potential problems and aspects that may not be otherwise obvious. Frameworks describing systems during their entire life (not just at particular points in time), also called life cycle architectures are commonly used in EA. 


\section{Enterprise Architecture Frameworks, GERAM and GERA}

Enterprises are highly complex systems. Therefore, sets of models (sometimes aggregated in architectural descriptions corresponding to viewpoints representing stakeholders (ISO/IEC 2007)) are produced using various languages in order to control this complexity and allow the enterprise architect and other stakeholders to focus on various aspects of the business. Other types of artefacts commonly used to structure knowledge in EA practice are modelling frameworks (MFs), methods, reference models, ontologies, metamodels, glossaries, etc; they are typically organised in architecture frameworks (AFs), some of which have underlying metamodels formally describing their structure. Currently there are several mainstream AFs, generic (e.g. PERA (Williams 1994), TOGAF (The Open Group 2006)) or aimed at various domains such as manufacturing (CIMOSA (CIMOSA Association 1996), ARIS (Scheer 1999)), defence (DoDAF (DoD Architecture Framework Working Group 2004), information systems (Zachman 1987), etc.

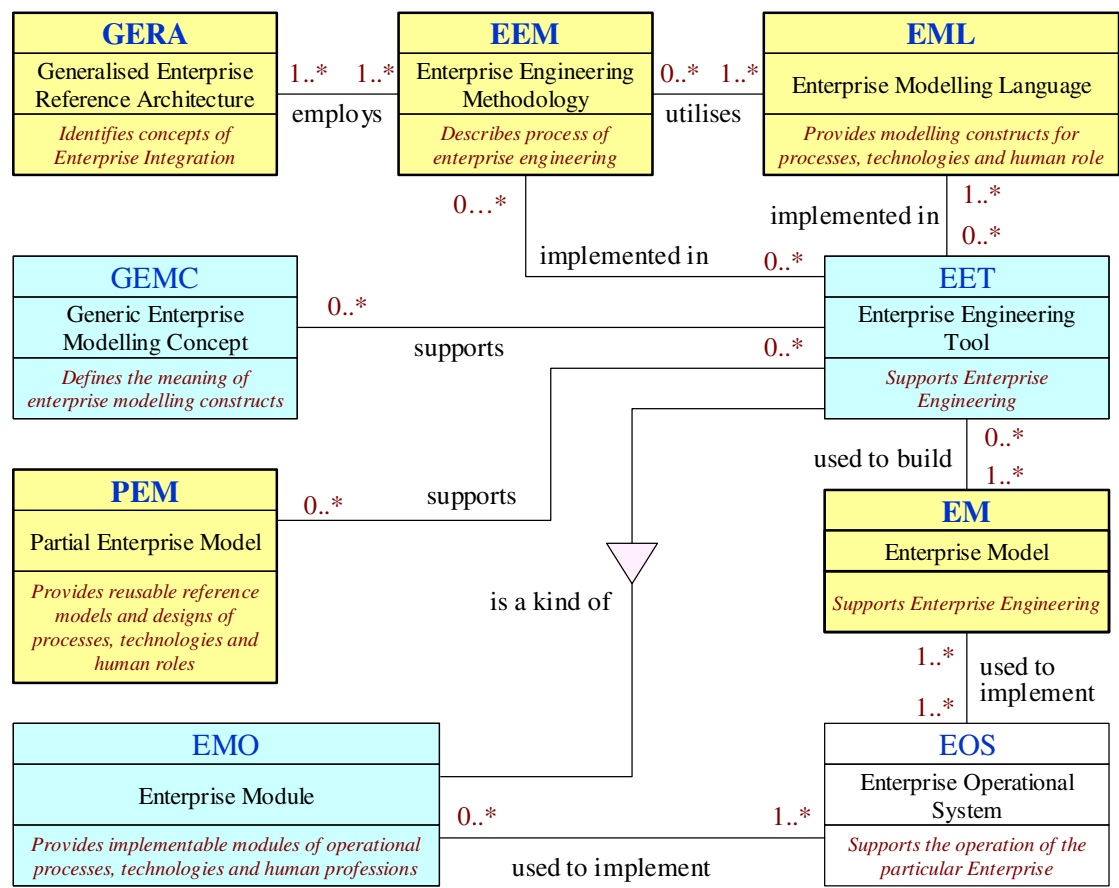

Fig. 1. A high-level meta-model of GERAM (based on (ISO/IEC 2005))

In this research we have selected a reference framework obtained by generalising other AFs and thus potentially expressive enough to contain all the elements necessary to achieve environmental management integration using EA artefacts. This AF is GERAM (Generalised Enterprise Reference Architecture and Methodology), described in ISO 15704:2000. GERAM has been used in practice to guide EA projects (Bernus, Noran et al. 2002), to assess other enterprise AFs (Noran 2003b; Noran 2003a; Noran 2005a; Saha 2007) and to build a structured repository of AF elements 
for a project management decision support system (Noran 2007a). For more details on GERAM see (ISO/IEC 2005).

The main component of the Reference Architecture of GERAM (called GERA, see Figure 1) is a MF containing an extensive set of aspects including life cycle, management, organisation, human and decision, corresponding to various stakeholder concerns (ISO/IEC 2007). A subset of GERA has been used as a modelling formalism in the creation of a life cycle-based business model as subsequently shown in this paper.

\section{A Meta-methodology for Enterprise Architecture Projects}

The paper argues that EA can provide an overarching and life cycle-based approach in setting up and operating an EM project aiming to produce an EMS in an integrated and coherent manner in relation to the host organisation and other relevant external entities. To illustrate this approach, the researcher has used a meta-methodology, or a "method to build methods' applicable for specific types of EA tasks (projects), based on an original approach abiding by EA principles. The meta-methodology, first defined in (Noran 2004; Noran 2005b) and tested in several case studies (Noran 2006; Noran 2007b; Noran 2008), employs a set of steps and sub-steps as shown in Figure2.

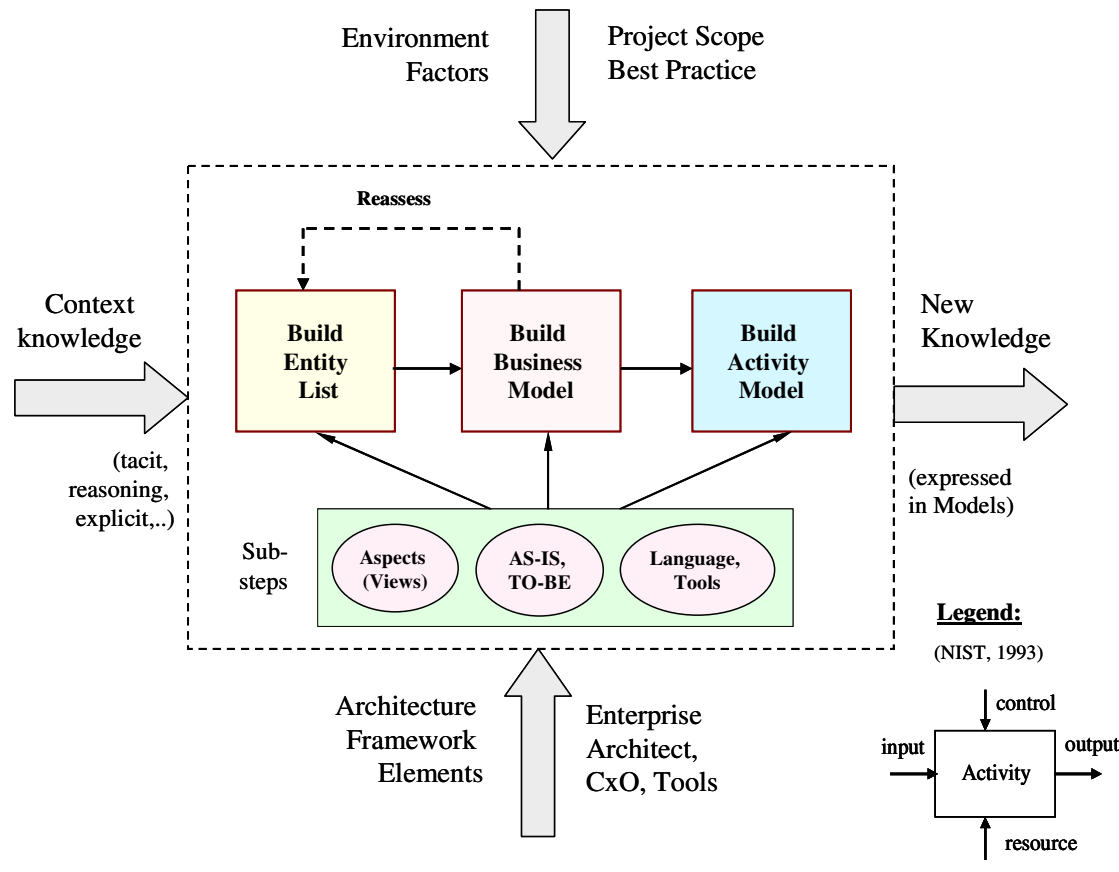

Fig. 2. Meta-methodology concept (Noran 2009a)

In the first step, the user is prompted to create a list containing entities of interest to the project in question, including project participants, target entities (organisations, other projects) and importantly, the project itself. The second step comprises the 
creation of business models showing the relations between the previously listed entities in the context of their lifecycles, i.e. illustrating how entities influence each other within each life cycle phase (several aspects can be represented, see sub-step one). The third step assists the user in inferring the set of project activities by reading and interpreting the previously represented relations for each life cycle phase of the project and other target entities. The resulting activities are then decomposed (using aspects selected according to sub-step one) to a level deemed suitable for the intended audience.

The first meta-methodology sub-step calls for the selection of suitable aspects (or views) to be modelled in each stage. The life cycle aspect must be present since it is essential to the meta-methodology. The selection of a MF is also recommended, as MFs typically feature structured collections of views that can be used as checklists of candidate aspects and their intended coverage. This sub-step also calls for the identification and reconciliation of any aspect/view dependencies. The second sub-step asks the user to determine if the present (AS-IS) state of the views previously adopted needs to be shown and whether the AS-IS and future (TO-BE) states should be represented in separate or combined models. Typically, the AS-IS state needs to be modelled when it is not properly understood by the stakeholders or when the TO-BE state is to be evolved from the AS-IS (no radical re-engineering is likely). The third substep requires the selection of suitable modelling formalisms and modelling tools for the chosen aspects according to the target audience and competencies and tools available in the organisation at present or in the future. Best-practice modelling principles such as formalism re-use and minimal number of languages are also underlying the formalism selection criteria.

Due to its scope and to space limitations, the paper will cover only the first and second meta-methodology steps, focusing in particular on the benefits of creating a business model in the context of the life cycles of all relevant participant entities.

\section{Application to the Environmental Management Project}

In this case, the meta-methodology deliverables are various models of the EM project and the EMS taking into consideration the internal and external business life cycle context. Since the management of the organisation and all other entities (business units, other organisations, agencies, laws etc) that need to be involved in the EM project and the EMS are to be included in the entity list (first step in Figure 2, left), their influence will be taken into account throughout the life cycle of the EM project and the EMS. An important prerequisite for EM integration into the organisation is thus fulfilled. As shown in Figure 2, the meta-methodology assists in creating new knowledge (in this case, how to go about setting up and operating the EM project and the EMS) based on context knowledge, i.e. the know-how of running the business including corporate culture, relations with suppliers, clients, authorities etc, typically available at middle and top management level. The involvement of these roles in the methodology creation process establishes the conditions for management buy-in and support for the upcoming EM project and for the early involvement of the EA department in the EM project. This will create the best conditions for the integrated development of the EMS and the supporting functions of the IS. 
Proposed members in the entity list are the company as a whole, business units, the EM project, the IS project, the EMS, the IS, environmental reports, NGOs, the government, Environmental Protection Agency (EPA), EM principles (e.g. 2R, TBL), EM laws, EM standards, EM frameworks, assessment and reporting frameworks, social responsibility standards, Quality Standards and EM consultants. The MF of GERA (see Figure 1) is adopted here as the most suitable to provide a formalism for the (mandatory) life cycle and other selected aspects.

In this case, the TO-BE state is incremental and based on the AS-IS (no radical redesign recommended when setting up an EMS). Therefore, in sub-step two, it the ASIS state should be represented for all aspects. While there is no tangible advantage in showing separate AS-IS and TO-BE states in the business model, it is very useful to do so in the decisional / organisational structure. This is because here it is imperative to clearly show where and how the functions of the EMS interact with the existing system so as to ascertain the degree of integration and effects of the EMS on the decisional and organisational structure of the host company. Separate AS-IS / TO-BE decisional / organisational models also help define several TO-BE scenarios.

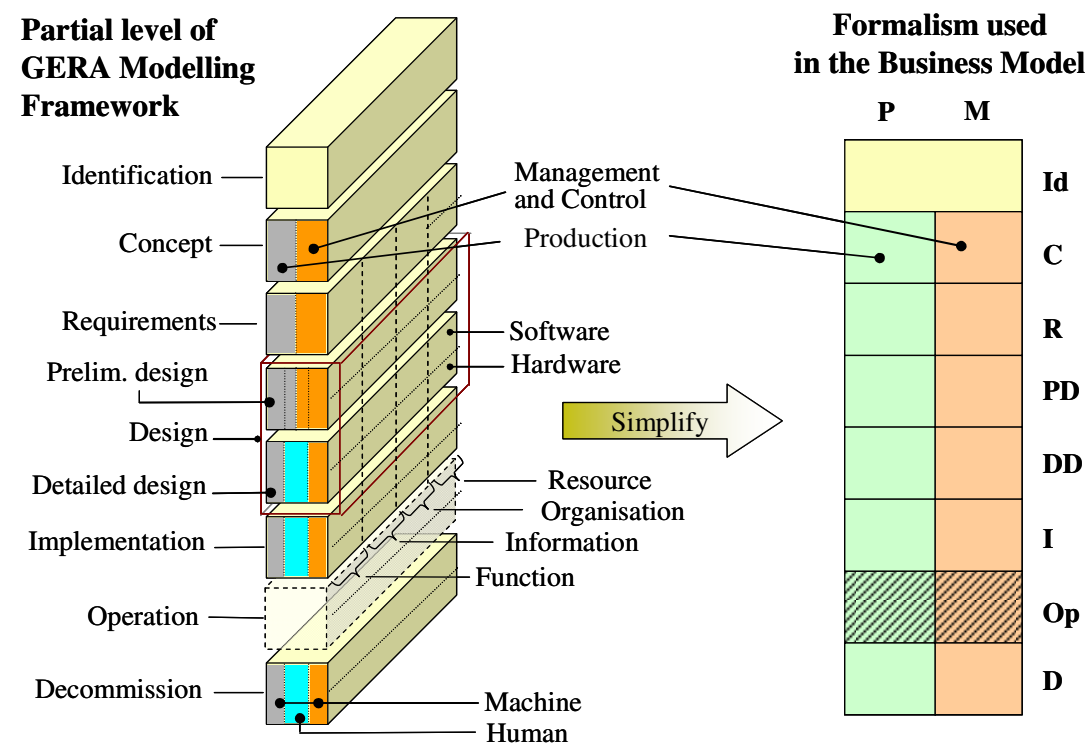

Fig. 3. Formalism used for the business model: simplified GERA MF

A modelling formalism based on the GERA MF was chosen for the business model (see Figure 3). GRAI-Grid (Doumeingts, Vallespir et al. 1998) was selected to represent decisional and organisational aspects (see Figure 5), together with a plain graphical editor as a modelling tool. GRAI-Grid was optimal in this case due to its ability to represent both the decisional and organisational aspects.

As shown in Figure 1, the business model is constructed in the second step based on context knowledge (often tacit and requiring eliciting by the meta-methodology facilitator) owned by stakeholders, i.e. $\mathrm{CxO}$, enterprise architect, top management, etc. 
A possible result is shown in Figure 4. As can be seen, the relations between the relevant entities can be explicitly represented for each life cycle phase. Note that some entities' life cycle representation has been reduced to the phase(s) relevant for the EM project and the EMS. For example, we are only interested in the Operation life cycle phase of Auditors, EM assessment / reporting frameworks, EM consultants, etc since they are not being designed / built as part of the EM project. The figure shows the relations between the company, the EM project, the EMS and the IS, thus facilitating a common understanding, building consensus and representing what needs to be done, step by step, at a high level.

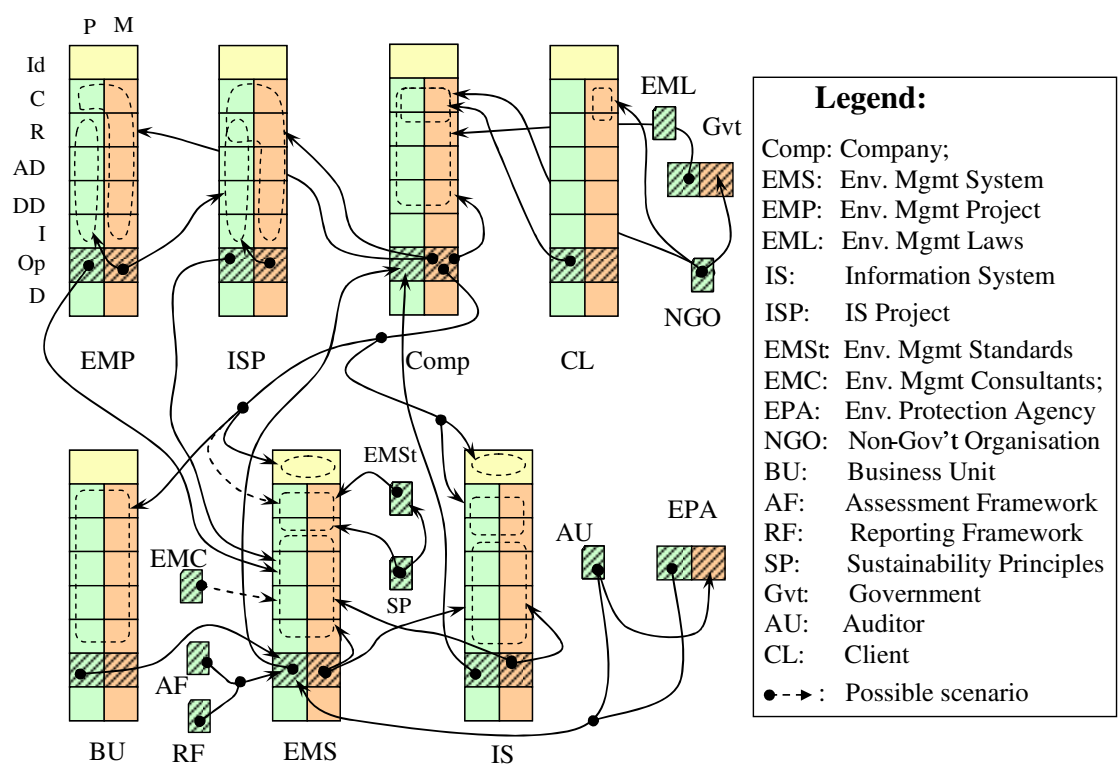

Fig. 4. Business model showing relations of relevant entities in the context of their life cycles

For example, the EMS is built by the EM project, with the possible involvement of consultants (EMC). The company is lobbied by NGOs and must abide by EM laws (EML). Auditors (AU) may perform certification audits (during the design of the EMS) or surveillance audits (to check if the EMS is still compliant). The EPA will look into the EMS operation and receive information from external auditors. Importantly, the EMS should be able to redesign itself (arrow from its Mgmt operation to its other EMS life cycles) to a certain extent and thus remain agile in the face of moderate EM regulation and market changes. Reaction to major changes will however be delegated to the upper company management via an EM project (EMP) (arrows from company (Comp) management operation to EMP and from EMP operation to EMS life cycles).

The arrow from the operation management side of the EMS to IS life cycles reflects the requirement to partially re-design the IS management and operation to integrate the EMS functions. On the other hand the IS is also influencing the design of EMS. Such inter-relations are detailed in the next meta-methodology steps as controls, inputs, decision frameworks, etc. 


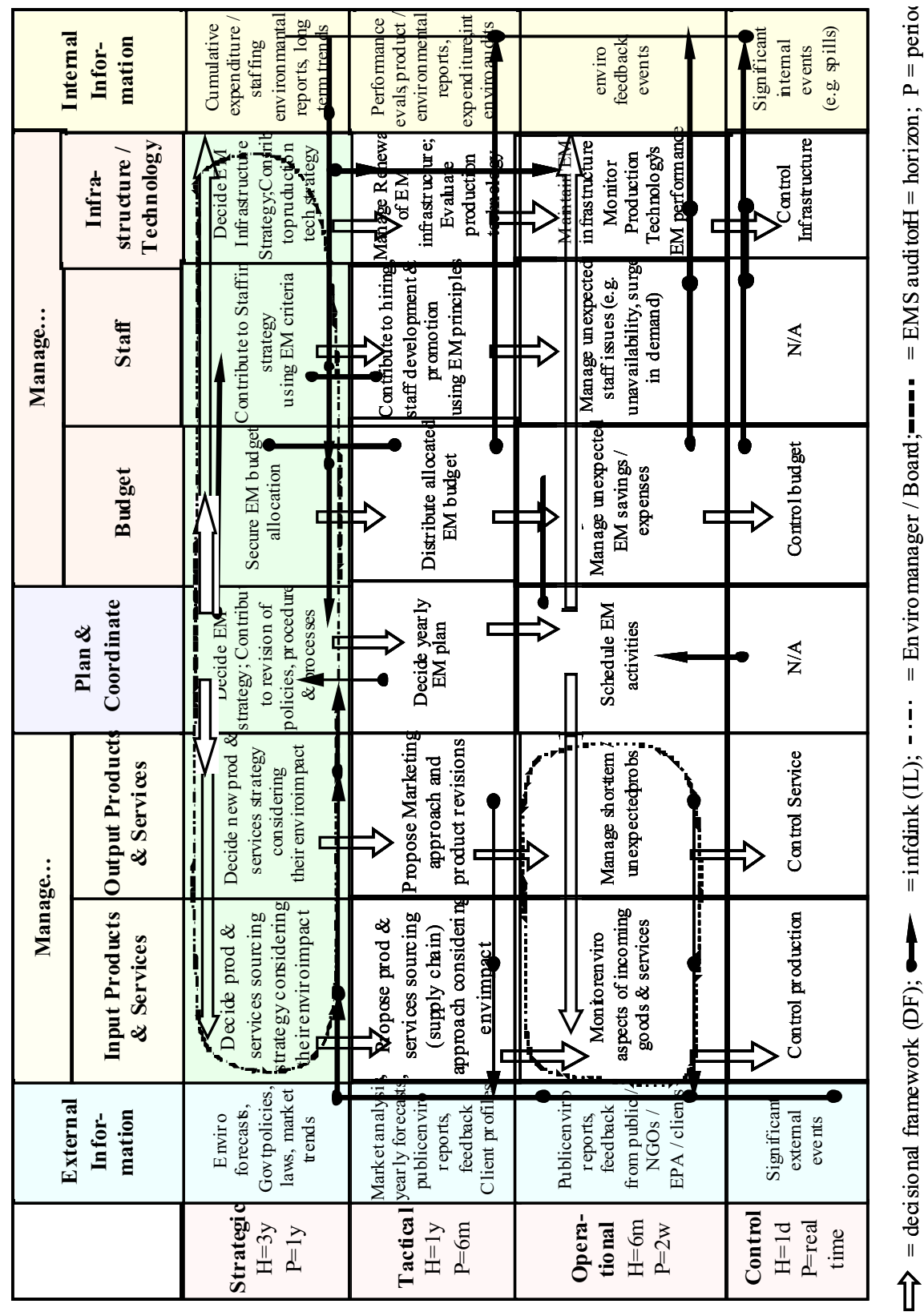

Fig. 5. Sample GRAI Grid for EM integration

The influences of other entities on the EMS and on the EM project EMP can also be interpreted as stakeholder concerns that translate in particular areas of interest being modelled and addressed. For example, the client may want to know how the 
mission and vision of the Company (the Concept area of Comp entity in Figure 4) addresses its environmental concerns, and the government (Gvt) will want to ensure that the Company abides by the public environmental concerns expressed in EM laws.

Models of the AS-IS and several potential TO-BE decisional and organisational aspects have also been constructed. For example, Figure 5 shows in a simplified form (using the GRAI-Grid formalism) a possible TO-BE decisional / organisational structure of an EMS as an add-on enabling the organisation to manage, benchmark and improve its environmental performance in an integrated manner (i.e. taking into account all relevant areas in a cross-departmental manner).

Detailed models including activity models of the third meta-methodology step are available in (Noran 2009b).

\section{Conclusions and Further Work}

Currently, businesses do not appear to achieve the maximum benefits from implementing and operating an EM project and an EMS. Firstly, there seems to be a lack of integration of the EM initiative with the business and its IS, especially at the strategic level. Thus, the management cannot take full advantage of the knowledge present in the environmental reporting mainly due to wrong format and/or level of aggregation. Secondly, an EMS needs to be driven internally and permeate all business areas in a consistent manner in order to produce organisational culture change, hence lasting effects. This paper has argued that such needs are best addressed by integrating EM in the ongoing EA initiative present in some form in every successful enterprise. EA can provide the necessary artefacts and the prerequisites for a coherent, cross-departmental and culturechanging approach ensuring business sustainability and profitability in the long term.

\section{References}

Bernus, P., Noran, O., et al.: Using the Globemen Reference Model for Virtual Enterprise Design in After Sales Service. Global Engineering and Manufacturing in Enterprise Networks (Globemen). In: Karvoinen, I., van den Berg, R., Bernuset, P., et al. (eds.) VTT Symposium 224, Helsinki / Finland, pp. 71-90 (2002)

Blackburn, W.R.: The Sustainability Handbook. EarthScan Publishers, Cornwall (2007)

CIMOSA Association, CIMOSA - Open System Architecture for CIM, Technical Baseline, ver 3.2. Private Publication (1996)

Clayton, A., Redcliffe, N.: Sustainability - A Systems Approach. Earthscan Publications, Ltd., Edinburgh (1998)

Coglianese, C., Nash, J. (eds.): Regulating from the Inside: Can Environmental Management Systems Achieve Policy Goals? RFF Press (2001)

DoD Architecture Framework Working Group (2004); DoD Architecture Framework Ver 1.0 (2007)

Doumeingts, G., Vallespir, B., et al.: GRAI Grid Decisional Modelling. In: Bernus, P., Mertins, K., Schmidt, G. (eds.) Handbook on Architectures of Information Systems, pp. 313-339. Springer, Heidelberg (1998)

Elkington, J.: Cannibals with Forks: The Triple Bottom Line of 21st Century Business (1998) EPA. Management Tools, Environmental Protection Agency, South Australia (2008)

GRI, Sustainability Reporting Guidelines. Sustainability Reporting Framework. Global Reporting Initiative (2002) 
Hunkeler, D. (ed.): Life-cycle Management. Society of Environmental Toxicology \& Chemist (2004)

ISO, ISO 14001:Environmental management systems - Requirements with guidance for use. International Standards Organisation (2004)

ISO/IEC, Annex C: GERAM. ISO/IS 15704:2000/Amd1:2005: Industrial automation systems Requirements for enterprise-reference architectures and methodologies (2005)

ISO/IEC, ISO/IEC 42010:2007: Recommended Practice for Architecture Description of Software-Intensive Systems (2007)

Mo, J.: The use of GERAM for Design of a Virtual Enterprise for a Ship Maintenance Consortium. In: Saha, P. (ed.) Handbook of Enterprise Systems Architecture in Practice, pp. 351366. IDEA Group, Hershey (2007)

Molloy, I.: Environmental Management Systems and Information Management - Strategic- Systematical Integration of Green Value Added. In: Gómez, J.M., Sonnenschein, M., Müller, M., Welsch, H., Rautenstrauchm, C. (eds.) Information Technologies in Environmental Engineering ITEE 2007 - (Porceedings of the 3rd International ICSC Symposium) (2007)

Nilsson, I.: Integrating Environmental Management to Improve Strategic Decision-Making. Chalmers University of Technology, Götteborg (2001)

Noran, O.: An Analysis of the Zachman Framework for Enterprise Architecture from the GERAM perspective. IFAC Annual Reviews in Control, Special Edition on Enterprise Integration and Networking (27), 163-183 (2003a)

Noran, O.: A Mapping of Individual Architecture Frameworks (GRAI, PERA, C4ISR, CIMOSA, Zachman, ARIS) onto GERAM. In: Bernus, P., Nemes, L., Schmidt, G. (eds.) Handbook of Enterprise Architecture, pp. 65-210. Springer, Heidelberg (2003b)

Noran, O.: A Meta-methodology for Collaborative Networked Organisations, School of Computers and Information Technology. Griffith University (2004)

Noran, O.: An Analytical Mapping of the C4ISR Architecture Framework onto ISO15704 Annex A (GERAM). Computers in Industry 56(5), 407-427 (2005a)

Noran, O.: A Meta-methodology Prototype for Collaborative Networked Organisations. In: Camarinha-Matos, L. (ed.) Collaborative Networks and Breeding Environments, Proceedings of the 6th IFIP Working Conference on Virtual Enterprises - PROVE 2005, pp. 339 346. Springer, Valencia (2005b)

Noran, O.: Refining a meta-methodology for collaborative networked organisations: a case study. Int. J. Networking and Virtual Organisations 3(4), 359-377 (2006)

Noran, O.: A Decision Support Framework for Collaborative Networks. In: Camarinha-Matos, L., Afsarmanesh, H., Novais, P., Analide, C. (eds.) Establishing the Foundation of Collaborative Networks, Proceedings of the 8th IFIP Working Conference on Virtual Enterprises - PROVE 2007, Guimaraes / Portugal, pp. 83-90. Kluwer Academic Publishers, Dordrecht (2007a)

Noran, O.: Discovering and modelling Enterprise Engineering Project Processes. In: Saha, P. (ed.) Enterprise Systems Architecture in Practice, pp. 39-61. IDEA Group, Hershey (2007b)

Noran, O.: A Meta-methodology for Collaborative Networked Organisations: Creating Directly Applicable Methods for Enterprise Engineering projects. Saarbrücken, VDM Verlag Dr. Müller (2008)

Noran, O.: A Decision Support Framework for Collaborative Networks. International Journal of Production Research 47(17), 4813-4832 (2009a)

Noran, O.: Engineering the Sustainable Business: An Enterprise Architecture Approach. In: Doucet, G., Gotze, J., Saha, P. (eds.) Coherency Management: Architecting the Enterprise for Alignment, Agility, and Assurance, pp. 179-210. International Enterprise Architecture Institute (2009b) 
Saha, P.: A Synergistic Assessment of the Federal Enterprise Architecture Framework against GERAM (ISO15704:2000 Annex A). In: Saha, P. (ed.) Enterprise Systems Architecture in Practice, pp. 1-17. IDEA Group, Hershey (2007)

Scheer, A.-W.: ARIS-Business Process Frameworks. Springer, Berlin (1999)

Shewhart, W.A.: Statistical Method from the Viewpoint of Quality Control. Dover Publications (1986)

The Open Group, The Open Group Architecture Framework (TOGAF 8.1.1 'The Book') v8.1.1 (2006)

TNEP, The Natural Edge Project, TNEP (2007)

UN World Commission on Environment and Development. Our Common Future (Brundtland Report). Oxford University Press, Oxford (1987)

Upham, P.: An assessment of The Natural Step theory of sustainability. Journal of Cleaner Production 8(6), 445-454 (2000)

Willard, B.: The Sustainability Advantage: Seven Business Case benefits of a Triple Bottom Line. New Society Publishers, Gabriola Island (2002)

Williams, T.J.: The Purdue Enterprise Reference Architecture. Computers in Industry 24(2-3), 141-158 (1994)

Zachman, J.A.: A Framework for Information Systems Architecture. IBM Systems Journal 26(3), 276-292 (1987) 